\title{
La Policía Nacional Civil a la defensiva
}

Durante las últimas semanas, la Policía Nacional Civil (PNC) ha dado mucho de qué hablar, y con sobrada razón, pues elementos de esta institución estatal se han visto involucrados en diversos actos delictivos, dentro de los cuales destaca su participación en grupos de exterminio cuyas prácticas guardan una gran semejanza con la de aquellos "escuadrones de la muerte" incrustados en los antiguos cuerpos de seguridad. Eso ha puesto a la corporación en la mira de las instituciones que trabajan, dentro y fuera del territorio nacional, por elevar los niveles de respeto a los derechos humanos de todas y todos los salvadoreños.

Que ahora abordemos el tema en esta espacio indica el elevado nivel de inquietud que nos generan estas situaciones, sobre todo por tratarse del organismo surgido de los acuerdos de paz que, originalmente, fue concebido para proporcionar seguridad y no para generar mayores niveles de intranquilidad entre la población.

$\mathrm{Y}$ no es algo nuevo ni fortuito el que estén sucediendo tales hechos. Cabe recordar que la Procuraduría para la Defensa de los Derechos Humanos (PDDH) -en su informe correspondiente a lo sucedido en el país durante 1996- expresó lo siguiente: "La determinación de las presunciones de responsabilidad en los actos constitutivos de violaciones a los derechos humanos ha recaído principalmente en la Policía Nacional Civil en el 55.7 por ciento $(2,700)$ de los casos, hecho que es congruente con la tendencia de comportamiento observada en el transcurso del año".

En lo que va de 1997, tal estado de cosas se ha mantenido. Prueba de ello son los datos revelados, recientemente, por la institución que preside la doctora Victoria Marina Velásquez de Avilés. En su último informe, la Procuraduría para la Defensa de los Derechos Humanos ratifica un hecho objetivo: la Policía Nacional Civil es la institución estatal más denunciada por actos que vulneran normas reconocidas en los ámbitos interno e internacional. Desde enero hasta mayo del año en curso, en sus oficinas se recibieron mil 100 denuncias contra unidades y personal de la policía. La mayoría de las quejas presentadas se relaciona con malos tratos, detenciones arbitrarias y muertes, tanto consumadas como fallidas.

También el personal del cuerpo ha sido denunciado por allanamientos de morada, detenciones por hechos no tipificados, trato inhumano a los detenidos y coacción e intimidación. Otro aspecto que hay que tomar en cuenta dentro de la problemática y su análisis es que, de acuerdo con el informe, las delegaciones del cuerpo más señaladas son las que se encuentran ubicadas en los departamentos de San Salvador, San Miguel y Sonsonate con 290, 146 y 100 denuncias, respectivamente.

Al observar los datos se concluye que -a lo largo de 1996- el promedio mensual de denuncias ciudadanas contra la Policia Nacional Civil fue de 225; considerando la misma fuente, se observa que la tendencia durante 1997 no ha variado: mensualmente se contabilizan, como promedio, 220 hechos. Como al año pasado, la mayor cantidad de quejas tiene que ver, sobre todo, con el irrespeto a los siguientes derechos: a la integridad personal (mil 80), a la libertad personal (821), a la seguridad y privacidad (375) y a la vida (145).

Lo anterior es una muestra de lo que sucede en la institución policial y lo mal que se encuentra. 
Sin duda, esta situación es preocupante y se vuelve, en realidad, más grave si nos ponemos a pensar que se trata de la corporación surgida hace poco tiempo para sustituir a otras de tan ingrato recuerdo. Más aún, al considerar que fue concebida originalmente - en los acuerdos de paz- para ser un soporte de la democracia y garantizar la defensa de los derechos humanos. Pero, la realidad de las situaciones antes mencionadas y el cuadro en su conjunto, nos indica una dirección contraria y sumamente peligrosa.

Lo peor es que, además, desde el interior de la misma Policía Nacional Civil se realizan acciones a distintos niveles pero siempre tendientes a ocultar los problemas. Una prueba de ello es lo que sucedió el jueves 5 de junio, cuando agentes del cuerpo capturaron a José Israel Vásquez, "testigo clave" en el caso de los policías involucrados en el homicidio de cuatro jóvenes supuestamente pertenecientes a las "maras" en Santa Ana.

Ese día, luego del reconocimiento en rueda de reos realizado en el Centro Penitenciario de Occidente, Vásquez fue interceptado por agentes policiales cuando era conducido a los juzgados. Sus captores le manifestaron que lo detenían por la violación de una joven el 18 de marzo de 1996. Según la información publicada, la orden de detención que le presentaron únicamente estaba firmada por el jefe de la delegación policial de Santa Ana, sub comisionado Douglas Omar García Funes.

Pero, inmediatamente después, el juez segundo de lo Penal de esa ciudad dictó orden de libertad en favor de Vásquez. De acuerdo con el funcionario judicial, no existían méritos suficientes para el arresto. No obstante, en una acción que sólo puede interpretarse como muestra de un mal entendido espíritu corporativo, se realizó la captura del testigo en cuestión tras el mencionado reconocimiento y, con ello, se lanzó otra señal más - negativa, obviamente- a quienes quieran animarse a testificar contra las o los miembros de una Policía que, según se observa, pretende volverse "intocable" y ajena a cualquier tipo de críticas que se le hagan desde la llamada "sociedad civil".

Con acciones de este tipo - absolutamente erradas, a todas luces - lejos de ayudar a localizar al paradero de los demás responsables en estos y otros hechos de violencia, la Policía Nacional Civil continúa sembrando más dudas entre la pobla- ción e incrementando su desconfianza en el cuerpo. Además, de esa forma se obstaculiza la buena marcha de las investigaciones judiciales necesarias para hacerle frente al fenómeno criminal en forma adecuada.

Pero no es extraño que en el terreno sus miembros actúen de esa manera si - para desventura nuestra- ese es el ejemplo que reciben desde la cúpula. No vayamos muy lejos: en respuesta al último de los informes de la Procuraduría para la Defensa de los Derechos Humanos, el director de la Policía Nacional Civil reaccionó como siempre. Rodrigo Ávila sostuvo que la institución estatal a su cargo, por naturaleza, siempre va a ser la más señalada como responsable de violaciones a los derechos humanos; también afirmó que muchas de las acusaciones carecen de fundamento. "Casi por costumbre -advirtió el ingeniero Ávila- el delincuente que es capturado por algún motivo, siempre busca atenuar su situación acusando a la policía de un mal procedimiento o de una detención arbitraria" (La Prensa Gráfica, 23 de junio, p. 12).

Días atrás, había negado enfáticamente la existencia de estructuras criminales dentro de la Policía Nacional Civil, tras la detención de sus dos subordinados acusados de ejecutar en Santa Ana a los presuntos "mareros". A eso nos tiene acostumbrados el director general: a rechazar, global y públicamente, los señalamientos que se le hacen y reconocer sólo lo que él considera válido, por lo general, en medio de justificaciones diversas como las señaladas.

Además de la negativa citada en el párrafo anterior, el ingeniero Ávila formuló de manera muy simple lo que él consideró como problema: algunos individuos dentro de la Policía Nacional civil -"malos elementos", dijo exactamente- "se aprovechan de su uniforme y condición para delinquir". La señora procuradora para la defensa de los derechos humanos calificó esa postura como "preocupante"; para ella, si no existen esas estructuras criminales en el interior del cuerpo, entonces algo está fallando en el momento de escoger a las personas que pretenden incorporarse al mismo. No obstante, al ser abordada por los medios de difusión tras la presentación de su último informe, la doctora de Ávilés sostuvo que el ingeniero Ávila era el funcionario que más cumplía las recomendaciones hechas por la Procuraduría para la Defensa de los Derechos Humanos. 
El ministro de Seguridad Pública tampoco se queda atrás en esta actitud; sólo que don Hugo Barrera utiliza la clásica táctica bélica de Clautzewitz, muy conocida en el ambiente deportivo y tan necesaria para la actual selección salvadoreña de fútbol: "la mejor defensa es el ataque". Cuando la procuradora insistió públicamente en la existencia de estructuras criminales dentro de la Policía Nacional Civil, el ministro le salió al paso exigiendo "pruebas concretas", a sabiendas de que esta procuraduría no tiene la capacidad instalada -recursos humanos y técnicos- ni el mandato constitucional para recabarlas. Ello, no obstante le corresponda -entre otras cosas - investigar casos de violación a los derechos humanos y practicar inspecciones para tal fin.

Que las autoridades encargadas de velar por la tranquilidad de la población reaccionen de esta manera no es nucvo, pero no por ello deja de ser inquietante. Siempre han estado a la defensiva con argumentos como los anteriores u otros. Ya hemos oído antes que muchos de los hechos que ocurren en el interior de la Policía Nacional Civil, mediante los cuales se afecta a la gente que debería servir, "son casos aislados y no institucionales". También hemos escuchado que lo que para muchas personas son estructuras criminales, para ellas sólo "son grupos infiltrados que quieren hacer daño a la institución".

Respuestas de ese calibre podrían interpretarse como síntomas de irresponsabilidad e inmadurez dentro las esferas oficiales para enfrentar los problemas que existen, los cuales están deteriorando progresivamente el cuerpo policial y la confianza que la gente debería tenerle. También podrían indicar que no existe la suficiente voluntad para mejorar esta importante institución y convertirla en lo que realmente debería ser: la garantía de nuestra seguridad, en un marco de respeto a los derechos humanos.

En ese marco, quien le presta un buen servicio al ingeniero Ávila y a don Hugo cuando defienden a la Policía Nacional Civil es su inspector general, Víctor Manuel Valle. Recientemente, dio a conocer un documento que incluye sus actividades durante los meses comprendidos entre enero y junio del presente año. Así, de nuevo cumplió con la formalidad de rendir un informe obligatorio a la procurada para la defensa de los derechos humanos cada seis meses, según el octavo artículo de la ley orgánica del cuerpo de seguridad.

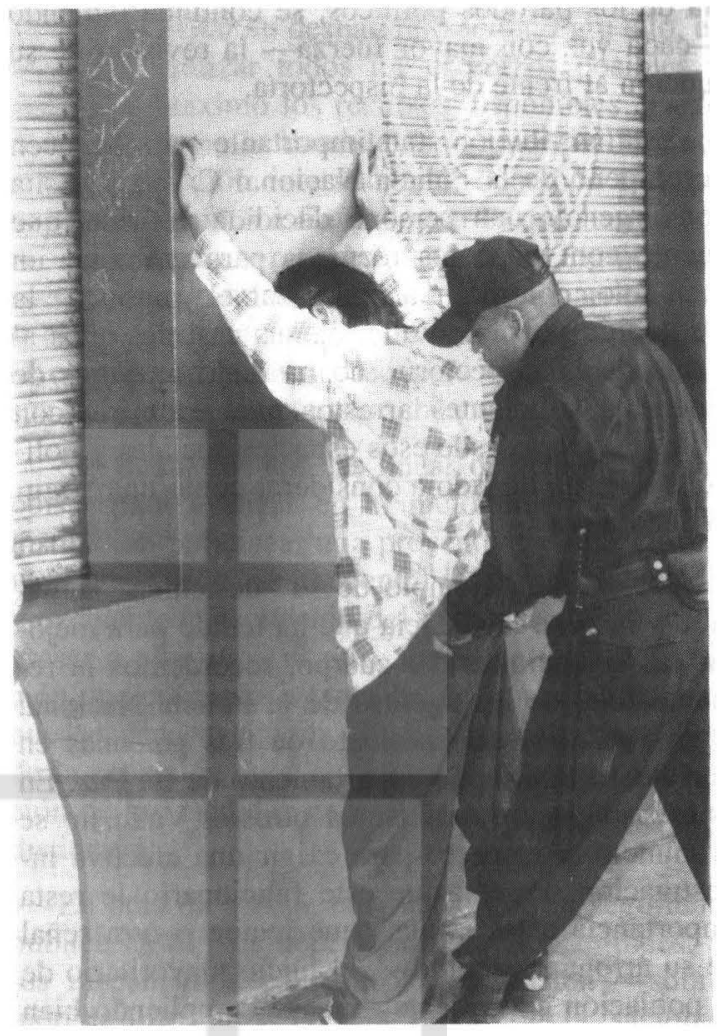

Según los datos proporcionados por Valle, durante ese período la entidad a su cargo recibió 229 denuncias. Lo anterior contrasta con las mil 100 denuncias que la población salvadoreña presentó durante cinco meses - de enero a mayo- en la Procuraduría para la Defensa de los Derechos Humanos contra el personal del cuerpo policial. Como ya vimos, en el transcurso de este año, la Procuraduría recibió un promedio mensual de 220 denuncias; mientras, el de la inspectoría tan sólo alcanzó las 38. Y con esos pobres resultados de su labor, el actual inspector se ufana de dos cosas: primero, que se ha incrementado el número de denuncias en un 46 por ciento, pues entre mayo y diciembre de 1996 el promedio mensual era de 26; segundo, que la gente tiene más confianza en acudir a la inspectoría y sabe dónde hacerlo.

Con lo anterior y como ya es costumbre -instalado en la autocomplacencia y cobijado en las declaraciones del presidente Calderón Sol a los medios de difusión-, Valle no tiene la capacidad para admitir que "le queda grande la camiseta". Sin embargo, tanto desde los organismos sociales interesados y conocedores del tema como de la mayo- 
ría de los partidos políticos, se continúa pidiendo — cada vez con mayor fuerza- la revisión de su función al frente de la inspectoría.

Esta institución, tan importante para el buen desempeño de la Policía Nacional CiVil, necesita con urgencia una persona decidida y firme, que cuente con todos los recursos para enfrentar un gran reto: contribuir a enderezar el rumbo de la institución policial. Valle, en sus casi dos años al frente de la inspectoría, no ha dado muestras de tener los suficientes arrestos para asumirlo con éxito. Por eso, desde esos espacios sociales y políticos se le ha llegado a considerar como una "figura decorativa".

Por citar un ejemplo de su "desteñida" actuación y la poca incidencia que ha tenido para mejorar las actuaciones del cuerpo, recordemos la reciente fuga de los agentes de la Policía Nacional Civil acusados del asesinato de tres personas en San Pedro Masahuat, departamento de La Paz. En este caso - como en tantos otros-Valle no se pronunció al respecto para exigir una efectiva investigación. Pese a que este funcionario le resta importancia a las críticas que recibe -otra señal de su arrogante actitud-, el juicio mayoritario de la población es evidente: no está cumpliendo bien su misión.

A él le corresponde señalar e investigar las acusaciones contra agentes que incurren en la realización de hechos delictivos, amparados en la impunidad que aún persiste en el país. Sin embargo, el número de denuncias contra la Policía Nacional Civil crece a un ritmo muy lento en la inspectoría y se encuentra muy distante de la preocupante cantidad que se registra en la Procuraduría, lo que revela - más bien- poca confianza en la primera institución y lo contrario en relación a la segunda.

Es claro que Valle no ha cumplido eficazmente la función que le corresponde; por eso está en la mira de un partido político, cuya representación en la asamblea legislativa ha pedido su destitución. De prosperar esa iniciativa, quizás se podría hacer algo para mejorar la inspectoría y la Policía Nacional Civil, en beneficio de la población. Pero, independientemente de lo que suceda con su futuro, parece que junio no es un buen mes para este funcionario pues hace exactamente un año, él evidenció su fragilidad e incompetencia. En ese entonces, "puso el grito en el cielo" quejándose de la persona que ocupaba el cargo de subdirector den- tro de la institución policiaca; hizo un escándalo y amagó con renunciar. Por esa época, se vio con claridad que no contaba con el apoyo sólido de nadie; ahora, con su actuación sumisa, parece que ya lo tiene del lado de sus jefes pero no de la población.

Pero, con o sin maquillaje, el caso es que se habla de la existencia de grupos ilegales dentro de nuestra policía que operan con impunidad, y exterminan supuestos "delincuentes" o miembros de "maras" sin una acción eficaz por parte de los mecanismos de control que existen, tanto dentro de la Policía Nacional Civil como en el Ministerio de Seguridad Pública. Es una presunción más que fundada. Asimismo, se observa poca disposición por parte de las autoridades para investigarlos y desarticularlos. Estas últimas, en lugar de adoptar una posición paternalista y "enconcharse", deberían ser más enérgicas para sanear la institución. No es suficiente que mencionen haber ordenado una investigación y que intenten consolarnos diciendo que pronto se resolverá todo; su actitud debería ser la de "tomar el toro por los cuernos" y entrarle de lleno al grave problema que tienen en sus manos.

Esas y otras situaciones graves que se dan en la Policía Nacional Civil por la actuación ilegal de sus elementos - de manera individual o actuando como parte de una determinada estructura "clandestina"- son el resultado de varios factores y hay que enfrentarlas con el concurso de la sociedad entera, a la cual pertenece. Sobre todo, se debe ir hasta el fondo en lo relativo al problema de la impunidad dentro de la institución. Para ello, sus responsables deben acercarse más a la población con resultados positivos en esta lucha.

Ya lo hemos dicho en otras ocasiones: la necesaria confianza que la gente debe tener en las autoridades encargadas de garantizar su seguridad, se encuentra fundada en una actuación transparente y respetuosa de la legalidad. Pese a que existe una diferencia abismal entre lo que actualmente tenemos y los antiguos cuerpos, falta mucho por hacer en este campo. En tal sentido, los datos que brinda la Procuraduría para la Defensa de los Derechos Humanos tienen que ser tomados en cuenta para empezar a trabajar duro, a fin de detectar y desaparecer - de una vez por todas - las estructuras criminales dentro de la Policía Nacional Civil; también, para comenzar a controlar y reducir la ejecución de actos que realizan sus agentes, me- 
diante los cuales se atenta contra la dignidad de las personas.

Pero no pretendemos que esos y otros señalamientos críticos que se hacen al funcionamiento del cuerpo, pongan a sus responsables contra la pared en una actitud claramente defensiva. Quedarse ahí no es suficiente ni satisfactorio para un pueblo urgido de vivir con justicia, democracia y paz. En esa línea, resultaría injusto no hacer mención de las numerosas muertes de agentes en el cumplimiento honrado y honroso de su deber; sobre todo, considerando las grandes limitaciones que se tienen para ello.

Se habla de supervisión inadecuada o falta de la misma por parte de los mandos hacia los puestos, cuando no se cuenta con todos los medios de transporte necesarios para cubrir grandes distancias. Así, las y los agentes que están en el terreno en repetidas ocasiones adoptan las decisiones menos acertadas y con ello se contribuye a que las intervenciones policiales - muchas veces-constituyan violaciones a los derechos humanos de la población. También, se mencionan problemas de comunicación debido a las fallas en el sistema de radio.

El aislamiento, la mala comunicación, los controles deficientes, la poca experiencia de su dirección y mandos medios, la diferencia de "estilos" en la conducción a distintos niveles, la escasa preparación y el bajo nivel cultural en muchos de sus elementos influyen -irremediable y negativamente- en la mala imagen que proyecta la Policía Nacional Civil.

Pero no es aceptable que lo anterior junto a lo grave del fenómeno delincuencial, se utilicen como excusas para cubrir lo que es inexcusable. Por ejemplo, para muchos sectores de la sociedad salvadoreña fue evidente la forma cómo se atacó al Departamento de Investigación del Crimen Organizado (DICO), con lo cual se logró disminuir su perfil. Así, se desperdició una buena posibilidad: la de contar con una herramienta eficaz, técnicamente bien preparada y con personal de calidad, para enfrentar esa "delincuencia especial" que existe dentro y fuera de la Policía Nacional Civil. Además, este departamento ha tenido que batallar con la resistencia interna de otras unidades y mandos para cumplir con su tarea.

Debe quedar claro que nuestro interés es uno: hacer de esta institución lo que se pensó hace unos años y así evitar su desnaturalización. Para ello, es necesario realizar todos los esfuerzos posibles y utilizar al máximo los recursos disponibles. Tanto el Estado como la llamada "sociedad civil", junto a la cooperación internacional, debemos trabajar en varios sentidos a fin de lograr lo que hasta ahora - por diversas razones- no se ha logrado: un cuerpo de seguridad integrado - desde arriba hasta abajo- por personas con vocación de servicio a la comunidad y capacidad para relacionarse con sus semejantes sin cometer abusos.

Sin duda, dos son las líneas de acción por impulsar para avanzar en el mejoramiento de esta institución policiaca: una preventiva y otra curativa. Por un lado, se encuentra la atinada selección y excelente capacitación del personal que va a ingresar a ella; por el otro, un proceso de depuración que comprenda tanto las acciones inmediatas que se necesitan como la fiscalización sostenida de la actuación de sus miembros, junto a la adopción de las medidas necesarias sin ningún tipo de distinción.

En aras de eso, la conducción de la seguridad pública en el país debe modificar sus actitudes, y los mecanismos de control que existen - sobre todo, la Inspectoría General de la Policía Nacional Civil- tienen que comenzar a funcionar de manera eficaz. No es posible permitir que, con su actuación, esos mecanismos encargados de fiscalizar el funcionamiento del cuerpo estén disminuyendo o anulando las investigaciones que deberían conducir al esclarecimiento de los hechos delictivos realizados por su personal. Hay quienes se atreven a sugerir que es necesario crear una instancia dedicada, exclusiva y permanentemente, a investigar el accionar de las y los elementos policiales a todo nivel -eso que llaman "asuntos internos" en las series estadounidenses-, pues ni las unidades de control y disciplinaria, ni la inspectoría general lo pueden hacer.

La conducción de la Policía Nacional Civil, por su parte, para ganar credibilidad y respeto, más bien debería mostrar una decidida voluntad a fin de esclarecer las actividades delictivas que tienen lugar en el país, dentro y fuera de sus filas, y evitar la tentación de desprestigiar y anular a las personas que se atreven a rendir testimonio contra sus agentes y en favor de la sociedad. Su función debería estar encaminada, mejor, a prestar toda la colaboración necesaria a las instituciones judiciales en el cumplimiento de su misión. 
En lugar de intentar descalificar a quienes consideran sus "enemigos", en la institución deberían preguntarse por qué suceden este tipo de cosas; deberían revisar por qué existen personas de dudosa calaña en su interior. Así, podrían encontrar respuestas más objetivas y comenzar a tomar las medidas del caso. Sin duda, lo que ahora señalamos no es casual. Mucho tiene que ver con ello el incumplimiento de las recomendaciones de la Comisión de la Verdad y del Grupo Conjunto para la Investigación de Grupos Armados Ilegales con Motivación Política. Entre otras cosas, dentro de ellas se establecía la necesidad de crear unidades especiales de investigación y se planteaba el necesario fortalecimiento de otros mecanismos, a fin de erradicar prácticas ilegales como las que ahora siguen ocupando nuestra atención.

No es posible "tapar el sol con un dedo" pretendiendo negar la existencia de estructuras de este tipo dentro de la Policía Nacional Civil, independientemente de que se quiera evitar mencionarlas con todas sus letras al decir que sólo existen "malos elementos". No podemos continuar permitiendo que, de esa manera, se favorezca su actuación impune. Es obvio que las hay; de ello han dado cuenta los observadores de las Naciones Unidas y la Procuraduría para la Defensa de los Derechos Humanos. A esta última institución, el ministro de Seguridad Pública le pidió recientemente una comunicación oficial donde se afirme esto y que contenga las pruebas que respalden lo dicho.

No hay que complicarse tanto. Basta que don Hugo tome la resolución de la procuradora sobre el caso de Manuel Adriano Vilanova Velver - por el cual se encuentran detenidos, después de mucha resistencia desde la cúpula policial, varios agentes de la Policía Nacional Civil- y que la lea detenidamente. En ella se brindan pistas, incluidos nombres y direcciones, sobre tales estructuras; las pruebas deben ser buscadas, con voluntad y hasta encontrase, por parte de los organismos encargados de eso. Así, pues, en lugar de "enredar" más las cosas lo que deberían hacer —en el Ministerio de Seguridad Pública y la dirección de la Policía Nacional Civil-es facilitar los medios para encontrar a los responsables y acabar con ellas de una vez por todas.

En febrero de 1992, cuando reflexionábamos en este espacio sobre la institución policial que estaba por crearse, dijimos que nos encontrábamos ante "una verdadera revolución en materia de seguridad pública, determinada desde la perspectiva de los derechos humanos, como una respuesta lógica y necesaria a las masivas y sistemáticas violaciones a los derechos fundamentales de la población salvadoreña ocurridas durante los últimos veinte años".

Y agregamos: "Un cambio de tal magnitud posibilitaría el nacimiento en la ciudadanía de una actitud de confianza y credibilidad, perdidas a raíz de la actuación de las anteriores corporaciones policiacas y tan necesarias para el establecimiento de un clima de seguridad entre la población".Lo anterior es una de las grandes deudas de lo que se conoce como el "proceso salvadoreño", pero seguimos creyendo que ese el camino que debemos recorrer. Es posible y necesario. 